\title{
TRIPLICIDADE E INTERAÇÕES ESPACIAIS: A CENTRALIDADE DOS TRÊS NÚCLEOS EM MARABÁ-PA
}

\author{
Mauro Emilio Costa Silva \\ Universidade Federal do Pará \\ Programa de Pós-Graduação em Geografia (PPGEO/UFPA) \\ Pará, PA, Brasil \\ maurobrasilgeo@yahoo.com.br \\ Núbia Nogueira do Nascimento \\ Universidade de Brasília \\ Programa de Pós-Graduação em Geografia (POSGEA/UnB) \\ Brasília, DF, Brasil \\ nascimento.nubia@hotmail.com
}

\begin{abstract}
RESUMO
Este artigo discute uma das propostas analisadas e desenvolvidas em pesquisa de doutorado, ainda em transição. Procuramos traçar definições de alguns teóricos para discutir as interações espaciais existentes entre três centros (núcleos) na cidade de Marabá-PA. A geografia é uma ciência que busca compreender a produção do seu principal objeto conceitual, espaço. Faz-se uma retrospectiva histórica da cidade de Marabá-PA, levando em consideração o processo de povoamento e urbanização e as atividades econômicas consolidadas ao longo dos anos. Busca-se a compreensão das interações espaciais da cidade de Marabá-PA e seus núcleos urbanos, Marabá Pioneira, Nova Marabá e Cidade Nova e seus distritos, que aqui não serão privilegiados, como Morada Nova, São Felix e Distrito Industrial. O estudo teve como procedimento metodológico pesquisa bibliográfica e duas entrevistas, realizadas com passageiros em táxis e com passageiros nos dois Terminais Rodoviários. Ao findar desse processo, obtivemos como resposta uma reflexão do intenso fluxo de pessoas e do processo econômico predominante na cidade de Marabá-PA.
\end{abstract}

Palavras-chave: Interação espacial. Espaço geográfico. Marabá-PA.

\section{TRIPLICITY AND SPACE INTERACTIONS: THE CENTRALITY OF THE THREE NUCLEUS IN MARABÁ-PA}

\begin{abstract}
This article discusses one of the proposals analyzed and developed in the Doctorate research, still in transition process. We try to draw definitions of some theorists to discuss the spatial interactions between three centers in Marabá, city of Para. Geography is a science that seeks to understand the production of its main conceptual object, space. A historical retrospective of Marabá is carried out, taking into account the process of settlement and urbanization and the economic activities consolidated over the years. It seeks to understand the spatial interactions of that city and its urban centers Marabá Pioneira, Nova Marabá and Cidade Nova, as well as its districts, which will not be privileged here, such as Morada Nova, São Felix and Distrito Industrial. The study had a bibliographical research and two interviews as a methodological method, carried out with passengers in a taxi and with passengers of two Bus Terminals. As result of this process we obtained a reflection of the intense flow of people and the predominant economic process in the city of Marabá, PA.
\end{abstract}

Keywords: Spatial interaction. Geographical space. Marabá-PA.

$\begin{array}{lllll}\text { Caminhos de Geografia } \quad \text { Uberlândia-MG } & \text { v. 21, n. } 74 & \text { Abr/2020 } & \text { p. 21-36 } & \text { Página } 21\end{array}$




\section{INTRODUÇÃO}

A Geografia, como uma ciência que se ocupa em compreender a produção com traço investigativo de simultaneidade de seu principal objeto conceitual, o espaço, visa a compreender a presença e a manifestação dos diversos fenômenos naturais e sociais que tanto se repetem quanto se ineditizam nos diversos pontos do globo, prática herdada dos fundadores dessa ciência.

A cidade emerge como um desses principais espaços, partindo dos estudos de caso sob a base de levantamentos teórico-metodológicos para nortear o pensamento na tarefa da identificação dos elementos singulares da produção e mesmo reprodução, para mensurar suas especificidades e pôr em contato com outras realidades na superfície para operacionalizar prováveis analogias. Não se tem a preocupação de se estabelecerem comparações interespaciais, mas sim de um maior entendimento da cidade hodierna e suas transformações, ciente no fato de que o processo de mudança na cidade advém, em certa medida, de suas relações com outras do mesmo e diferente porte, por meio das interações espaciais que ampliam ou criam papéis e funções para as cidades.

Essas novas ou (re)criadas atribuições funcionais são resultantes da reestruturação espacial. As interações espaciais forçam um novo desenho da cidade, que se reestrutura, diferentemente da materialidade do espaço e da cidade; e o urbano também se renova não apenas pela materialidade como pelo percebido das práticas socioespaciais. As práticas socioespaciais são ancoradas na seguinte acepção: "[...] A prática espacial consiste numa projeção "sobre o terreno" de todos os aspectos, elementos, e momentos da prática social" (LEFEBVRE, 2013, p. 15).

Nesse sentido, intenciona-se compreender na cidade de Marabá-PA as interações espaciais entre os três núcleos urbanos (Marabá Pioneira, Nova Marabá e Cidade Nova). De acordo com a revisão do "Plano Diretor Participativo" (2011), essas áreas são também consideradas "Distritos", juntamente com outros de níveis secundários, que não serão privilegiados na pesquisa, a saber: Morada Nova, São Félix e o Distrito Industrial, áreas que contribuem para a caracterização de cidade multinucleada por meio de seus fragmentos de centralidade econômica.

A cidade como um sistema urbano que integra seus fragmentos em torno do centro, a composição e o conteúdo do centro e da área central são privilegiados por desempenharem um papel de comando e por possuírem, mas não somente nestes, a centralidade econômica. No caso marabaense, os três núcleos empiricamente considerados como centros e áreas centrais como partes de um todo da cidade, necessariamente, interagem espacialmente, pela condição que exercem. Dessa forma, emerge o jogo capitalista de trocas dialéticas de complementariedades e competitividades, sendo essas trocas que aqui se pretende vislumbrar.

Assim sendo, tem-se como exemplo dessas centralidades econômicas, localizadas no núcleo da Nova Marabá, o Shopping Center Pátio Marabá e, na Marabá Pioneira, a orla turística e sua condição de centro histórico e tradicional. Esses fatores por si só estabelecem fluidez e interações espaciais que tendem a centralizar, (re)centralizar essas áreas sob a égide de lógicas econômicas definidoras e redefinidoras de conteúdos urbanos.

\section{DOIS MOMENTOS SOCIOESPACIAIS DE MARABÁ}

\section{Do meio natural à formação territorial e à gênese de Marabá}

Os processos de povoamento e produção espacial partem de uma premissa, a apropriação da natureza, cujas riquezas atraem e mantêm o grupo, sendo esse o início de muitas formações territoriais. Conforme postula Santos (2008a, p. 133), "o meio natural era fase da história na qual o homem escolhia da natureza o que era fundamental do exercício da vida e valorizava diferentemente essas condições naturais". Assim, a natureza exerce a função de atração, fixação e participação na vida dos habitantes influenciando as esferas da vida comum. No caso da região amazônica, é revestida por uma extensa floresta equatorial densa e fechada, também entrecortada por grandes rios como Amazonas, Tocantins, Araguaia entre outros.

A região dispõe de uma ambiência que teve forte influência na gênese de suas cidades, assim, comumente, as mais antigas se localizam às margens ou próximas aos rios. A cidade de Marabá possui sua morfologia sob a condição da influência do curso dos rios Itacaiúnas e Tocantins, o que a caracteriza como uma cidade ribeirinha. São consideradas cidades ribeirinhas aquelas que surgiram às margens dos rios, e seus habitantes mantêm fortes relações socioculturais e econômicas com os

$\begin{array}{lllll}\text { Caminhos de Geografia } & \text { Uberlândia-MG } & \text { v. 21, n. } 74 & \text { Abr/2020 } & \text { p. 21-36 }\end{array}$


recursos hídricos (OLIVEIRA, 1999; TRINDADE JR. 2012; TRINDADE, 2012). Importante observar que tal condição hidrográfica, periodicamente, provoca enchentes no Marabá Pioneira.

Quando analisa o padrão dendrítico "rio-várzea-floresta", Porto-Gonçalves (2006, p. 79) explica que o termo expressa três ecossistemas em que as cidades se relacionam em maior ou menor intensidade até os dias atuais (especialmente as cidades antigas), carregando consigo elementos da natureza hidrográfica, o que explica a denominação de cidades ribeirinhas. Tal conceituação prescinde de análise aprofundada, pois a priori não basta se localizar às margens do rio para ser considerada como tal. Em outras palavras,

As cidades ribeirinhas, diferentemente das cidades beira-rio, têm fortes articulações socioeconômicas e culturais com a escala geográfica local e regional; articulações estas que traduzem estreita relação com o rio, não simplesmente pela localização absoluta daquelas em relação a este último, mas principalmente pelas relações econômicas e socioculturais que incluem o rio como um dos importantes elementos que referenciam espacialidades e territorialidade urbanas (TRINDADE JR., 2012, p. 11).

Para o autor, a simples localização às margens do rio não basta para que a cidade seja considerada ribeirinha. Assim,

Estar à beira do rio constitui-se uma das principais condições para que uma cidade amazônica possa ser considerada ribeirinha. Não se aceita, todavia, que toda cidade que esteja situada às margens de um rio tenha automaticamente credenciais que a reconheçam como tal (TRINDADE JR., 2012, p. 37).

O rio, como uma forma de transporte de grande utilidade por parte dos seus habitantes, é uma característica de cidade ribeirinha na Amazônia, haja vista que em suas margens as relações sociais são orientadas pela dinâmica do rio, que determina o tempo de ida e volta, ou seja, a fluidez de pessoas e mercadorias. A cidade ribeirinha é relacionada ao meio natural e é, antes de tudo, ditada pela natureza.

A importância em incorporar a dimensão da natureza, nesse caso os rios, se deve ao fato de que o crescimento da estrutura urbana de Marabá conformada em três núcleos foi, em parte, propiciado pela presença da água, que dividiu a cidade em porções de terra desconectadas espacialmente, situação espacial minimizada com a construção das pontes sobre os rios ligando as três áreas entre o fim do século XX e início do XXI. Os rios ainda participam da vida urbana dos citadinos marabaenses de modo diferenciado, confirmando a tipologia de Marabá como cidade ao mesmo tempo ribeirinha e cidade a beira-rio, combinando temporalidades distintas tanto pela formação como pela manutenção da relação social com as duas características de cidades.

Entretanto a cidade partilha de elementos gerais de outras que sofreram fortemente a urbanização nos moldes do capitalismo brasileiro, sendo essa vertente urbana que mais interessa, ao garantir para Marabá a conexão aos processos socioespaciais multiescalares. O município de Marabá tem destaque no Estado não apenas pela condição de centro sub-regional, considerado como uma cidade média, como também por ser um entroncamento rodoferrofluvioviário, além do aeroporto, reunindo condições para sua nodosidade na região do sudeste paraense.

Conforme dados estatísticos do IBGE (2010), Marabá-PA, em 2016, tinha uma população de aproximadamente 266.932 habitantes, sendo considerada uma cidade média. A seguir, podemos verificar algumas características do mapa físico da região.

Podemos observar no Mapa 1 a importância da nodosidade de Marabá para o estado do Pará e Amazônia oriental. Isso se deve a sua capacidade de viabilizar os fluxos, interescalarmente, por meio dos diversos modos de transporte de que dispõem. Observa-se que,

Hoje, além de sua importância econômica para o sudeste paraense, é notável seu papel como entroncamento aeroviário e rodoferroviário para as cidades menores de sua sub-região. Ademais a articulação de Marabá com as regiões vizinhas, inclusive fora da Amazônia, por meio das novas vias de circulação, fez da mesma uma das principais cidades da Amazônia brasileira, após os maiores centros urbanos regionais. Assumem importância, nesse caso, a rodovia Transamazônica (BR-230), PA-150, BR-222 e a Estrada de Ferro Carajás, que a articulam a diversos municípios considerados espaços de novas oportunidades econômicas e de investimentos capitalistas (TRINDADE JR., 2011, p. 7). 
Figura 1 - Localização de Marabá no sudeste do Pará.

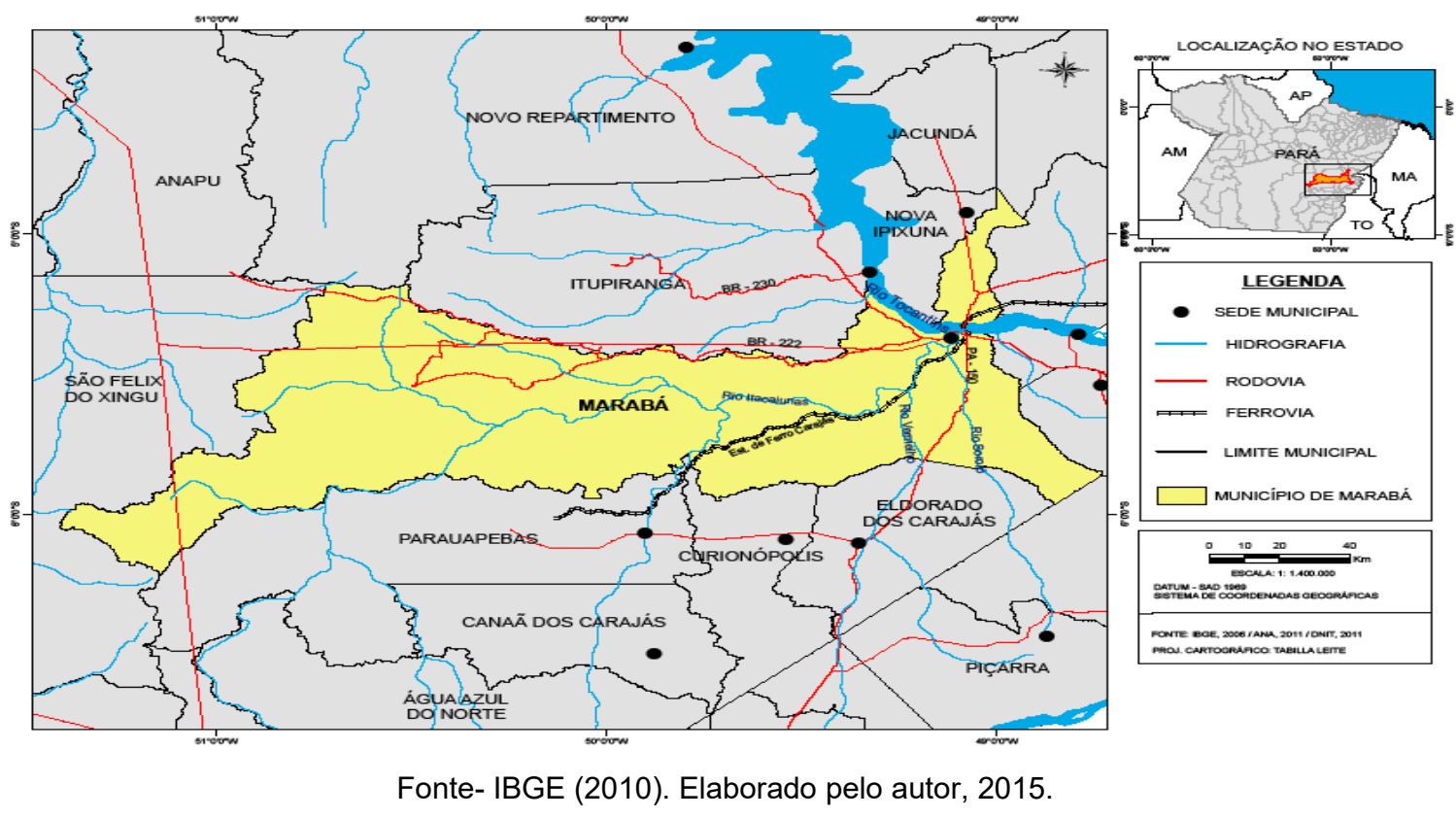

Ainda que a historiografia revele a importância de entroncamento para Marabá, os direcionamentos que as atividades econômicas tomaram levaram a fluxos migratórios e determinadas concentrações intraurbanas. Esses foram fatores que ampliaram o município na condição de entroncamento regional e, consequentemente, o tecido da cidade.

\section{Do Meio Técnico ao Científico-Informacional: reestruturação urbana e da cidade de Marabá (1970 A 2017)}

Na década de 1970, a região amazônica, sobretudo na faixa oriental, sofreu grandes intervenções do governo federal. Dentre as cidades eleitas, estava Marabá, considerada uma das principais cidades da região por fatores locacionais, geo-históricos, econômicos e políticos, que ampliaram seu destaque regional. Dessa forma,

Compreender o processo evidenciado nas paisagens urbanas de Marabá pressupõe analisar o papel exercido pelas políticas desenvolvimentistas empreendidas para o território amazônico, principalmente a partir dos anos 1970. A incorporação definitiva da região Amazônica ao processo de planejamento nacional se consubstanciou no programa de desenvolvimento, no documento de metas e bases para ação do governo, o qual orientou a elaboração do I PND (Plano Nacional de Desenvolvimento) 1972/74 (RODRIGUES, 2013, p. 120).

A cidade de Marabá recebeu vultosos investimentos públicos e privados nos últimos quarenta anos, demarcando cada qual com suas características no espaço em um movimento dialético, que se revela no tempo ora mais ora menos democrático, compreendido no conteúdo dessas constantes mudanças sociais. Ainda que Marabá apresente fatos que apontem para perda territorial e econômica em um cenário de acordos, como na emancipação de municípios que antes faziam parte de seus limites, a exemplo de Parauapebas (Lei $n^{\circ}$ 9.443/88, de 10 de maio de 1988, Prefeitura de Parauapebas, 2016), município onde se encontra a maior província mineralógica do planeta, ou mesmo o declínio de suas atividades tradicionais como a castanha ou borracha, conseguiu manter-se como cidade polarizadora no sudeste paraense pelos diversos recursos e condições espaciais favoráveis para isso.

O advento das rodovias, com destaque a Transamazônica (BR-230), inaugurada em 1974, é considerado um vetor de relativa crise enquanto cidade ribeirinha em Marabá, pois ocorreu uma reestruturação na cidade, na medida em que seu traçado entrecorta o intraurbano, inclusive margeando duas áreas centrais (Nova Marabá e Cidade Nova). A rodovia supracitada fazia parte de um programa de integração nacional direcionado à Amazônia por meio do sistema rodoviário. Com esse propósito, 
[...] criou-se, em 1960, a ligação rodoviária entre Belém e o Sudeste do país através de Brasília e, mais tarde, as rodovias para Porto Velho (BR-364) e Santarém (Cuiabá-Santarém). Deste modo, a produção industrial do Sudeste alcançou a Amazônia, ao mesmo tempo que esta passou a enviar matérias-primas para o Sudeste, como é o caso da cassiterita (CORRÊA, 1987, p. 57).

O sistema rodoviário exerce um grande peso na redefinição da cidade pelo alcance que desemboca na morfologia espacial. Para Spósito (2004, p. 65), "o termo morfologia é designativo daquilo que se refere à forma, mas o conceito de morfologia urbana vai muito além da análise das formas urbanas em si, embora as contenha". A rodovia Transamazônica passou não apenas a fazer parte da forma como também influenciou nas relações urbanas que por elas foram eivadas, logo, sua emersão é concebida no conteúdo da cidade.

Figura 2 -Traçado das Rodovias em Marabá.

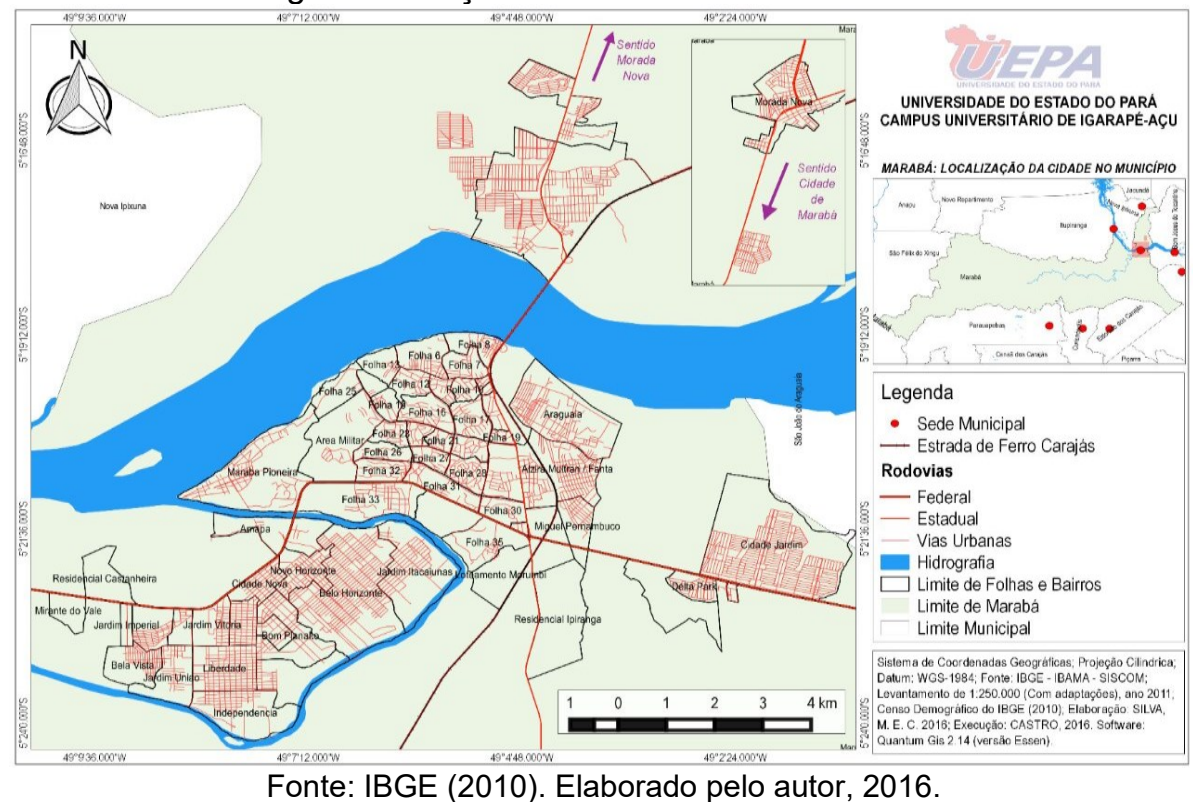

Importante ressaltar que as construções das rodovias não ocorreram de modo isolado, sendo parte de uma comunhão de intervenções por agentes públicos que tinham interesse em estruturar a região para atender demandas econômicas, isto é, facilitar o acesso e estabelecer em Marabá uma reserva de mão de obra visando a atender a demanda da mineração.

A implementação do sistema rodoviário se, por um lado, facilita a migração de mão de obra, por outro diversifica e intensifica a dinâmica de serviços e comércio pelos novos fluxos trazidos pelas conexões escalares. Dessa maneira assenta-se o padrão sociogeográfico "estrada-terra firme-subsolo" (PORTO-GONÇALVES, 2006).

Tal padrão em referência é constituinte de eventos que se evidenciaram na Amazônia e em Marabá por meio da ligação terrestre, o uso do solo continental e suas riquezas subterrâneas provindos da mineração. Prudente ressaltar que o padrão espacial calcado na estrada não nulificou as relações da cidade com do rio, havendo sim justaposição entre os dois padrões e até potencializado sua dinâmica urbana. Pode-se dizer que

A cidade do rio também se anima pela estrada, o que nos faz vê-las não como resultados de um passado estático ou de um futuro avassalador, mas como um espaço-tempo presente, denso e vivo, cujos atributos maiores são a simultaneidade e a dinamicidade (MALHEIRO; TRINDADE JR., 2009, p. 4).

A atividade da mineração trouxe mais do que o padrão "estrada-terra firme-subsolo" para Marabá, pois o setor exige a extração, transformação da matéria-prima e escoamento para exportação, requer do espaço a capacidade de suporte à atividade e novas lógicas aos citadinos das cidades próximas à mina por meio de uma vida urbana cercada dos ethos da mineração, materializado, por exemplo, pela receita dos impostos trazida para o município. Afirma-se que 
A arrecadação de receita proveniente dos impostos coletados com a atividade mínero-metalúrgica é uma importante fonte de obtenção de recursos por parte dos governos municipais para o investimento em políticas públicas. Um dos pontos positivos para os municípios que estão sob a influência direta dos projetos de mineração na Amazônia, especialmente o estado do Pará, é a arrecadação da Compensação Financeira pela Exploração de Recurso Mineral (CFEM), um importante medidor financeiro da importância dos repasses de investimentos para os municípios e estados com expectativa em termos de ganhos econômicos a partir dos projetos das companhias mineradoras (PALHETA et al., 2014, p. 368).

Um dos instrumentos para a compreensão do nível de arrecadação de receitas municipais não apenas para apoiar, mas também para criar projetos infraestruturais que rebatem ao espaço em escala local é a observância na participação do PIB na região, como no caso de Marabá, inserida no sudeste paraense.

Importante ressaltar que o município de Marabá vivenciou a perda da várias siderúrgicas nos dez últimos anos, permanecendo abertas apenas duas, SIDEPAR (Siderúrgica do Pará S/A) e SINOBRAS (Siderúrgica Norte Brasil S.A.) (Trabalho de campo, 2016). Esses efeitos econômicos, inexoravelmente, aprofundaram mazelas sociais como o desemprego, reproduzindo a pobreza na população, constituindo-se em uma das principais características socioespaciais marabaense.

Em uma perspectiva de crise econômica, o fechamento das siderúrgicas, com exceção das duas já citadas em Marabá, implica redução do ritmo das transformações infraestruturais e (re)modelagem do espaço, permitindo pensar em uma perspectiva de um cenário que não mais justifica a propalada retórica da intensa urbanização das principais cidades amazônicas nas últimas décadas, não havendo perspectivas teóricas que mostrem um movimento para o campo por parte das pessoas desempregadas. Nesse sentido,

Por outro lado, em contraposição as demais cidades médias do país, em que as cidades deste porte apresentam uma melhor qualificação do trabalho e um nível mais elevado de qualidade de vida de sua população, no caso das cidades médias amazônicas, elas tendem a apresentar o empobrecimento de sua população e condições de vida urbana precárias (RIBEIRO, 2010, p. 9).

Ainda que seja possível mencionar um freio no processo de urbanização regional nos últimos anos, com destaque em Marabá, atribuído pela decadência ou falência de pequenos e médios produtores ligados à siderurgia, por outro lado, pode-se atribuir outras atividades para a circulação de emprego e renda que se soma com a mineração, verificada no quadro a seguir.

Quadro 1 - Indicadores Básicos do Município de Marabá-PA.

\begin{tabular}{|l|l|}
\hline INDICADORES & \\
\hline Área (em km 2) & $15.128,416$ \\
\hline Densidade Demográfica (Hab/km 2) & 15,45 \\
\hline População Total (estimada em 2014) & 257.062 \\
\hline IDHM-2010 & 0,668 \\
\hline PIB per capta-2011 (Em reais/ano) & $15.678,02$ \\
\hline PIB - Agropecuária (valor adicionado) em mil & 93.503 \\
\hline PIB - Indústria (valor adicionado) em mil & 906.757 \\
\hline PIB - Serviços (valor adicionado) em mil & $2.150,151$ \\
\hline Pessoal ocupado total & 46.789 \\
\hline Rendimento médio, por domicílio urbano (em R\$) & $2.299,24$ \\
\hline Rendimento médio, por domicílio rural (em R\$) & $1.185,34$ \\
\hline
\end{tabular}

Fonte - Instituto Brasileiro de Geografia e Estatística-IBGE, 2010. 
Pode-se constatar, de acordo com os dados do Quadro 1, que a renda gerada pelos serviços supera a agropecuária e da indústria, denotando que o circuito produtivo densificou-se na cidade a equipando de técnicas correlatas ao seu funcionamento, apontando para o espaço urbano marabaense como a relação indissociável entre o sistema de ações e sistema de objetos (SANTOS, 2008b). A capacidade de instalação e funcionamento de serviços exclusivos em uma dada fração da cidade conforma uma característica de centralidade sempre em movimento e portadora de conteúdo.

Uma das consequências do processo de reestruturação da cidade em questão é o surgimento de possíveis áreas centrais (núcleos): Nova Marabá e Cidade Nova, que se uniram com o centro principal; e a Marabá Pioneira, produzindo a multinuclealidade do tecido urbano. Houve também a expansão espontânea de duas áreas consideradas como núcleos secundários, São Felix e Morada Nova, estes, considerados como "distritos de expansão", além do Distrito industrial (Plano Diretor Participativo, 2006), núcleos que não serão privilegiados na pesquisa.

A emersão de possíveis duas novas áreas centrais (núcleos) aponta para um processo espacial marcado pela combinação e articulação de agentes de setores distintos que criam mecanismos de reprodução e acumulação inerentes aos rigores da mundialização da economia, o que rebate no urbano e o leva para um jogo recíproco de diferentes atividades presentes na cidade, ligadas por relações de "interdependência global" (SANTOS, 2012), o que impõe a troca concebida distante sobre o uso da proximidade percebida.

O caso marabaense em que os três núcleos se fazem presentes em seu espaço intraurbano demonstra um crescimento urbano espraiado, porém com interações de possíveis complementariedades de serviços e comércio que possivelmente apenas um centro tradicional não teria condições de cumprir. Desse modo, faz-se necessária a compreensão das especificidades em termos de forma e função que cada centro exerce e o processo a que se vincula.

A artificialização do espaço no contexto hodierno no âmbito das cidades não ocorre sem redefinições urbanas e da cidade e, por isso, as transformações que a cidade vivencia por meio das formas refuncionalizadas ou criadas no geral estão sob o primado da ciência. Desse modo, os núcleos marabaenses e suas centralidades terão como aporte teórico-metodológico os princípios do período técnico-científico-informacional. A atividade mineradora norteou a redistribuição dos papéis das cidades desempenhadas na região do sudeste do Pará, tendo a cidade de Marabá como principal nó de articulação, delegando-se para esta uma função primaz que necessariamente corresponderia pela capacidade espacial de atender as demandas territorialmente localizadas.

A instalação de atividades inéditas ou mesmo conhecidas reconfigura as localizações intraurbanas, engendrando em Marabá uma situação espacial propensa ao surgimento de áreas centrais e distribuição de centralidades, retirando o caráter monocêntrico até então existente. Em estudos mais recentes, Spósito (2013) vem aludindo uma possível superação da relação entre centro-periferia que tanto marcou as cidades brasileiras no século XX, e essa perspectiva é atribuída pelas metamorfoses intraurbanas que têm o centro como principal foco de alteração.

As reestruturações urbanas por certas e lógicas econômicas de forte rebatimento intraurbano dispensam ao centro o encaminhamento para o restante da cidade sobre o novo momento socioespacial que passa a incorporar, ou seja, o centro irradia as principais ordens, garantido também pelas verticalidades interescalares.

Para o restante da cidade, as reestruturações urbanas nem sempre reafirmam sua interação com o centro, que tende também a diversificar e espraiar continuamente suas atividades, conformando-se em áreas centrais e mesmo novos centros e áreas centrais afastadas e, em menor grau de importância, subcentros, produzindo, dessa maneira, a cidade "Multi(Poli)cêntrica" (SPOSITO, 2013). A autora pondera os prefixos "Multi" e "Poli" alertando que existe diferença quanto à compreensão da centralidade não como um fenômeno concreto, e sim como uma condição.

As duas modalidades de centralidades são destoadas por dois principais motivos, a saber: a primeira está atrelada à diversificação de áreas com atributos de centralidade e alcance escalar, predominantemente, local; enquanto a segunda opera com maior profundidade e intensidade nas mesmas transformações socioespacias, porém, alterando substancialmente a natureza e dinâmica do lugar e um alcance escalar regional, nacional e mesmo internacional. A policentralidade supera a lógica inicial da multicentralidade que uma área central pode exercer. Esse processo efetua-se da seguinte maneira: 
Dinâmicas mais recente observadas, que se combinam, mas superando a lógica que orienta a sua formação. É atinente ao aparecimento de grandes superfícies comerciais e de serviços, que redefinem de modo profundo, a estrutura espacial que vinha se estabelecendo no decorrer do tempo, não são todas as áreas centrais, mas, especialmente, hipermercados modernos de grandes grupos do setor, Shopping Centers, centros especializados de grande porte (de negócios, de serviços médico-hospitalares, de feiras, de festas etc.) (SPÓSITO, 2013, p. 75).

Na estrutura espacial da cidade de Marabá, sob a luz do fenômeno, policentrismo, é possível tecer que as modificações intraurbanas instrumentalizadas por meio do referido processo permite pensar em relações de concorrência, complementariedade e mesmo subordinação entre as áreas centrais dos núcleos, Marabá Pioneira, Nova Marabá e Cidade Nova, desvelado por meio das interações espaciais.

As superfícies policêntricas exercem uma influência significativa na vida urbana dos citadinos, quando reorienta os fluxos prenhes de novas práticas socioespaciais. Essa situação espacial vem se desenhando na cidade de Marabá com o policentrismo evidenciado com as modificações de um evento articulador e moderno que os três centros apresentam.

Figura 3 - Organização dos Núcleos urbanos da cidade de Marabá.

MAPA DE LOCALIZAÇÃO DOS NÚCLEOS URBANOS DE MARABÁ (PA)

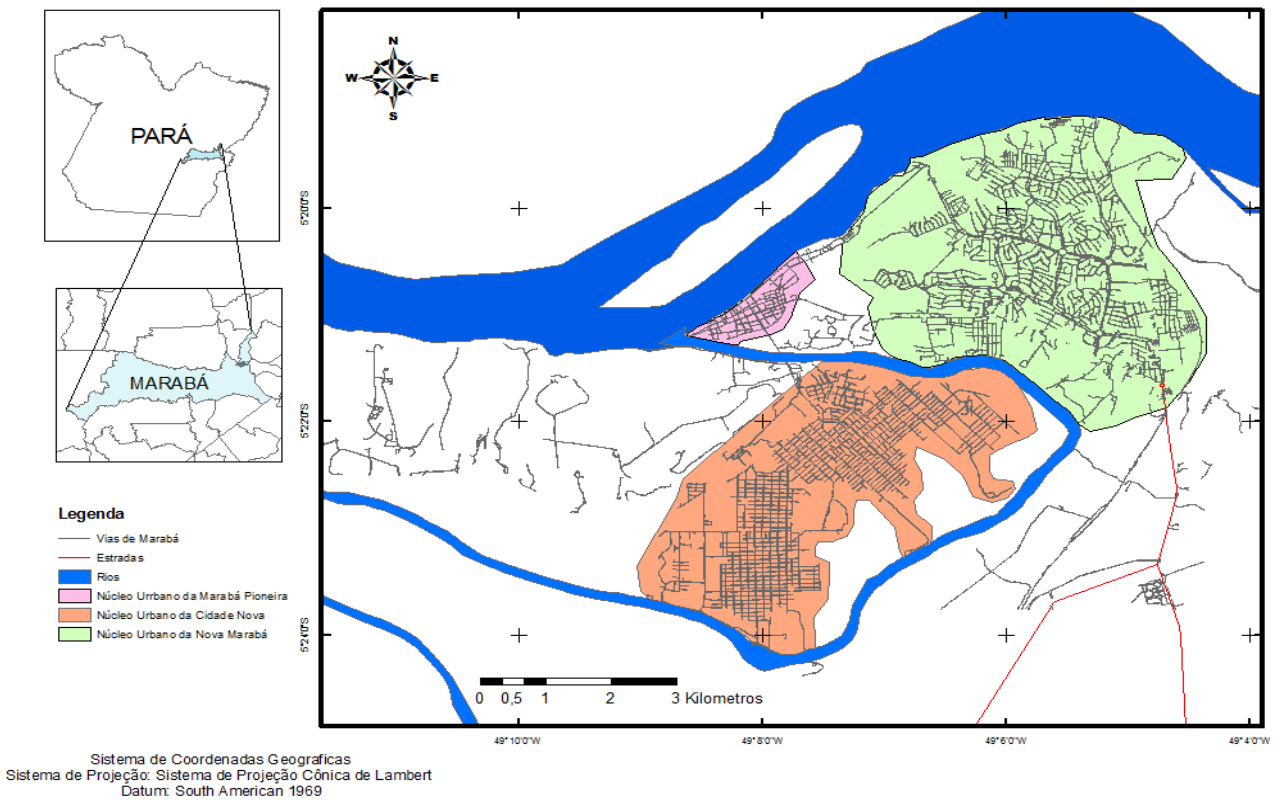

Fonte - Elaborado por Camila Sousa, 2014.

A localização dos três núcleos no sítio urbano marabaense expressa descontinuidade espacial. Ab'Saber (1957, p. 11) considera o sítio urbano como "um pequeno quadro de relevo que efetivamente aloja um organismo urbano". De acordo com o mapa da Figura 3, são em média $6 \mathrm{~km}$ entre si, levantando a hipótese da necessidade de atender aos assentamentos humanos que foram se aglomerando nesses lugares por vários fatores, sendo condição e meio para o surgimento de dois novos núcleos na cidade (Nova Marabá e Cidade Nova), um desdobramento particular do processo de urbanização de Marabá.

A formação dos núcleos mais recentes em Marabá coloca em evidência a centralidade pelos processos redefinidores de seu conteúdo. Observa-se que,

Para se compreender a constituição da centralidade os fluxos são os elementos determinantes. Fluxos que são incrementados pelas comunicações e telecomunicações que são traduzidas em trocas, decisões, gestão, controle e irradiação de valores. A dinâmica de concentração e dispersão cria e recria 
centralidades que irão ocupar e valorar diferentemente e diferencialmente territórios no tecido urbano e se traduzem em segregação socioespacial e na fragmentação urbana. Por isso, compreendemos o caráter processual da centralidade, em complementação ao centro, expressão territorial. A centralidade é expressão da dinâmica de definição/redefinição das áreas centrais e dos fluxos no interior da cidade (WHITACKER, 2010, p. 2).

De acordo com o autor, a centralidade é cambiante no tecido urbano e é determinada pelos fluxos das trocas e das atividades que the cercam, inerente à reprodução do capitalismo que diferencia o espaço pelo movimento de concentração e dispersão. Em tempo, a concentração condiz com a polarização intraurbana, enquanto a dispersão com a marginalização, a dicotomização espacial evidencia a divisão territorial do trabalho entre áreas e 0 aprofundamento das contradições socioespaciais como corolários da centralidade. A centralidade, por ser um fenômeno urbano com características próprias de formação, funcionalidade e especificidades, alcança em certa medida ritmo e a vida urbana da cidade.

\section{A FORÇA DOS TRÊS CENTROS MARABAENSES E AS INTERAÇÕES ESPACIAIS INTRA E INTERURBANAS}

Os três centros (núcleos) possuem objetos espaciais comuns, haja vista o uso do solo para fins residenciais e comerciais exigentes de equipamentos urbanos semelhantes, além dos serviços variados (simples e complexos). Para uma cidade multinucleada como Marabá, deve-se levar em consideração que o processo histórico e outros fatores produziram também especificidades de funções que caracterizam o espaço, confirmado pelo uso do solo por citadinos marabaenses e de outras cidades.

Como proposta metodológica, adotamos a observação participante, que significa para Turra Neto (2012, p. 243) "[...] uma interação face a face, com o grupo estudado, com objetivo de produzir informações", o que ocorreu por meio da utilização de um táxi lotação que circula entre os três núcleos (centros) urbanos: Marabá Pioneira, Cidade Nova e Nova Marabá. Visou-se apreender de modo dialógico informações com os passageiros e o taxista sobre os motivos dos deslocamentos, bem como a utilização dos serviços e equipamentos dos três centros (núcleos) para criar uma base empírica que sustente a interação espacial intra e interubana. O ponto de partida ocorreu entre o percurso da Cidade Nova a Marabá Pioneira. A pesquisa foi realizada com alguns passageiros que fretavam táxi-lotação para deslocamento, com objetivo de verificar o motivo da interação espacial intraurbana na cidade de Marabá entre seus centros. A resposta a essa indagação podemos verificar nas falas transcritas:

Entrevistador: Motorista, quanto custa à passagem entre os três centros? Taxista: 3.75 reais. Entrevistador: $O$ que você pretende fazer na Marabá Pioneira? Passageiro Mulher 1: Vou visitar a minha mãe, já morei na Nova Marabá Velha e estou aqui. Entrevistador: Por que mudou para a Cidade Nova? Passageiro Mulher 1: Por causa das enchentes na Velha Marabá. Entrevistador: Como é o movimento de passageiros ao longo do mês? Taxista: É bom entre os dias 01 a 16 do mês depois é só pinga pinga (Trabalho de campo, agosto, 2016).

Os referenciais teóricos utilizados para compreender a estruturação do sistema urbano da cidade de Marabá na porção da área central da Marabá Pioneira foram confirmados com a narrativa acima no tocante às enchentes como fator natural para a migração sazonal e permanente de seus habitantes para outras áreas da cidade, sobretudo a área central da Cidade Nova.

Outra observação é a dinâmica da circulação intraurbana mais intensa na primeira quinzena do mês, denotando a necessidade da utilização dos equipamentos urbanos de serviços, simples e complexos, juntamente com o comércio até o período mencionado. Assim sendo, não há manutenção da circulação interna durante o mês inteiro, considerado intermitentemente.

Entre o percurso da Marabá Pioneira e Nova Marabá:

Entrevistador: Quantos quilômetros daqui até a Nova Marabá? Taxista: Qual dos terminais você vai ficar? Entrevistador: O novo né? Que tem mais jeito de antigo!

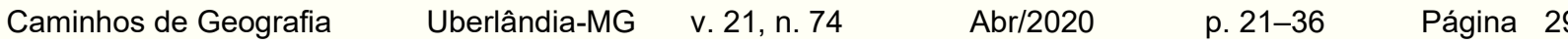


Entrevistador: Dá uns seis km? Taxista: é. Entrevistador: eu queria perguntar o motivo que faz vocês irem de um centro ao outro? Passageiro Mulher 1: Resolver negócio. Eu e meu pai é pra resolver negócio. Passageiro Mulher 2: Marabá é uma ilha, e todo inverno a água sobe e invade as casas e o pessoal começou a expandir, a mudar pros outros centros, tem muita gente que continua lá. Todo ano quando enche eles saem, mas voltam. E o que me fez sair de Marabá Velha (Pioneira) foi tudo isso: a enchente. Entrevistador: Mas essa enchente hoje em dia está menor? Passageiro Mulher 2: Bem Menor. Entrevistador: Mas ainda enche algumas casas? Passageiro Mulher 2: algumas casas. Passageiro Homem: Esse ano não encheu. Passageiro Mulher 2: Ano passado também não encheu. Entrevistador: Você mora onde? Passageiro Mulher 2: Na cidade Nova. Passageiro Homem: Eu moro na Cidade Nova, tava pra velha, agora eu tô indo pra Cidade Nova. Passageiro Mulher 2: é porque fica dividido assim, o comércio, alguns setores da saúde. Eu por exemplo tô vindo do Hospital Regional. Entrevistador: Mas você mora onde? Passageiro Mulher 1: Na Morada Nova. Entrevistador: Eu conheço. Entrevistador: Aí veio pra Velha e da Velha tá indo...? Passageiro Mulher 1: Vou pra Nova e de lá que eu vou embora. Entrevistador: Mas vocês conseguiram resolver tudo o que queriam? Passageiro Mulher 1: Aqui já! Aí eu vou pro mercado. Por que na Morada Nova só tem um correio. Não tem lotérica, não tem nada, então não resolve. Tudo é aqui ou na Nova Marabá. (Trabalho de campo, Agosto, 2016)

As narrativas clarificam a importância do núcleo da Nova Marabá quanto a objetos espaciais de serviços atrativos e quanto à interação espacial intraurbana. É recorrente a justificativa das enchentes para a repulsão dos habitantes da Marabá Pioneira, porém a dinâmica hidrográfica dos rios Itacaiúnas e Tocantins vêm reduzindo o volume das cheias a cada ano, diminuindo a problemática de abandono das habitações. Os dois centros (núcleos) secundários, Morada Nova e São Félix, ainda que tenham uma função destinada à habitação, não conseguem suprir a demanda de serviços simples aos seus moradores, compelindo-os a migrar, nesse caso, para os centros da Nova Marabá e Cidade Nova, em face de melhor assistência de serviços, principalmente os ligados à saúde.

A condição centrípeta, no que concerne aos serviços médicos, dada à fração espacial da Nova Marabá, tem raízes na sua formação, ao ter sido o único centro (núcleo) planejado da cidade. Não obstante o insucesso das ruas e avenidas em formato de árvore de castanheira, outros equipamentos como o Hospital foram exequíveis como atividade prevalecente dessa área. A Nova Marabá abriga os dois terminais rodoviários da cidade, contribuindo para sua centralidade por meio de fluxo migratório intra e interurbanos. A segunda análise do estudo consiste em verificar a quantidade de entrevistados que migram para outras cidades circunvizinhas para diversos fins. Podemos observar isso com mais clareza nos Quadros 2, 3 e 4.

Quadro 2 - Consulta aos passageiros transeuntes no Terminal Rodoviário e Feira Miguel Pernambuco.

\begin{tabular}{|c|c|c|c|c|c|}
\hline $\mathrm{N}^{\circ}$ & IDADE & SEXO & ORIGEM & DESTINO & MOTIVO \\
\hline 01 & 70 & $\mathrm{M}$ & ARAGUATINS-TO & MARABÁ-PA & VISITA \\
\hline 02 & 18 & $\mathrm{M}$ & SANTA LUZIA DO PARÁ-PA & XINGUAAR-PA & TRABALHO \\
\hline 03 & 33 & $\mathrm{~F}$ & MANAUS-AM & NOVO REPARTIMENTO-PA & SAÚDE \\
\hline 04 & 42 & $\mathrm{~F}$ & ARAGUAIANA-TO & PARAUAPEBAS-PA & SAÚDE \\
\hline 05 & 49 & $\mathrm{M}$ & TEREZINA-PI & ALTAMIRA-PA & SAÚDE \\
\hline 06 & 22 & $\mathrm{~F}$ & ARAÍSES-MA & PINHEIRO-MA & VISITA \\
\hline 07 & 32 & $\mathrm{~F}$ & CANÃA DOS CARAJÁS-PA &
\end{tabular}

Fonte - Elaborado pelos autores (2016). Em 26/8/2016 (Sexta-feira) às 10h. 
Quadro 3 - Continuação da consulta aos passageiros transeuntes no Terminal Rodoviário e Feira.

\begin{tabular}{|c|c|c|c|c|c|}
\hline $\mathrm{N}^{\circ}$ & IDADE & SEXO & ORIGEM & DESTINO & MOTIVO \\
\hline 01 & 36 & $\mathrm{~F}$ & PARAUAPEBAS-PA & MARABÁ-PA & VISITA \\
\hline 02 & 58 & $\mathrm{M}$ & $\begin{array}{l}\text { BREJO GRANDE DO } \\
\text { ARAGUAIA-PA }\end{array}$ & MARABÁ-PA & VISITA \\
\hline 03 & 34 & $\mathrm{M}$ & BELÉM-PA & MARABÁ-PA & TRABALHO \\
\hline 04 & 21 & $\mathrm{~F}$ & CURIONOPOLIS-PA & BOM JESUS DO TOCANTINS-PA & VISITA \\
\hline 05 & 47 & $\mathrm{~F}$ & PARAUAPEBAS-PA & MARABÁ-PA & NEGÓCIOS \\
\hline 06 & 36 & $\mathrm{M}$ & MARABÁ (ZONA RURAL)-PA & MARABÁ-PA & MORADIA \\
\hline 07 & 33 & $\mathrm{M}$ & PARAUAPEBAS-PA & MARABÁ-PA & VISITA \\
\hline 08 & 50 & $\mathrm{~F}$ & ALTAMIRA-PA & ARAPIRACA-PB & SAÚDE \\
\hline 09 & 38 & $\mathrm{~F}$ & AMARANTE-MA & ANAPU-PA & MORADIA \\
\hline 10 & 31 & $\mathrm{~F}$ & PALMAS-TO & MARABÁ-PA & VISITA \\
\hline 11 & 32 & $\mathrm{M}$ & BELÉM-PA & MARABÁ-PA & TRABALHO \\
\hline 12 & 32 & $\mathrm{~F}$ & PALMAS-TO & TUCURUI-PA & VISITA \\
\hline 13 & 25 & $\mathrm{M}$ & PALMAS-TO & MARABÁ-PA & VISITA \\
\hline 14 & 20 & $\mathrm{~F}$ & MARABÁ-PA & IMPERATRIZ-PA & VISITA \\
\hline 15 & 33 & $\mathrm{M}$ & JOÃO ALFREDO-PE & ANAPU-PA & TRABALHO \\
\hline 16 & 21 & $\mathrm{~F}$ & MARABÁ-PA & ESTREITO-MA & VISITA \\
\hline 17 & 23 & $\mathrm{~F}$ & TOCANTINOPOLIS-PA & CANÃA DOS CARAJÁS-PA & VISITA \\
\hline 18 & 18 & $\mathrm{~F}$ & MARABÁ-PA & ELDORADO DOS CARAJÁS-PA & LAZER \\
\hline 19 & 23 & $\mathrm{~F}$ & MARABÁ-PA & SÃO JOÃO DO ARAGUAIA-PA & VISITA \\
\hline 20 & 41 & $\mathrm{~F}$ & PARAUAPEBAS-PA & TUCURUÍ-PA & SAÚDE \\
\hline 21 & 31 & $\mathrm{M}$ & MARABÁ-PA & MARABÁ (CAMPO)-PA & LAZER \\
\hline
\end{tabular}

Fonte - Elaborado pelos autores (2016). Em 27/8/2016 (sábado) às 9h15.

Quadro 4 - Consulta aos passageiros transeuntes no Terminal Rodoviário de Marabá, para obtenção de informações no segundo Terminal Rodoviário da cidade

\begin{tabular}{|c|c|c|c|c|c|}
\hline $\mathrm{N}^{\circ}$ & IDADE & SEXO & ORIGEM & DESTINO & MOTIVO \\
\hline 01 & 57 & $\mathrm{~F}$ & $\begin{array}{c}\text { CANÃA DOS CARAJÁS- } \\
\text { PA }\end{array}$ & MARABÁ-PA & VISITA \\
\hline 02 & 61 & $\mathrm{M}$ & MARABÁ-PA & TEREZINA-TO & MORADIA \\
\hline 03 & 32 & $\mathrm{M}$ & MARABÁ-PA & ANAPU-PA & $\begin{array}{l}\text { PESQUISA } \\
\text { DE CAMPO }\end{array}$ \\
\hline 04 & 21 & $\mathrm{~F}$ & PALMAS-TO & MARABÁ-PA & ESTUDO \\
\hline 05 & 36 & $\mathrm{~F}$ & ITUPIRANGA-PA & XINGUARA-PA & VISITA \\
\hline 06 & 34 & $\mathrm{~F}$ & ABEL FIGUEIREDO-PA & BELÉM-PA & SAÚDE \\
\hline 07 & 65 & $\mathrm{~F}$ & ITUPIRANGA-PA & SÃO GERALDO-PA & NEGÓCIOS \\
\hline 08 & 37 & $\mathrm{M}$ & LUIZ DOMINGUES-MA & $\begin{array}{c}\text { ELDORADO DOS CARAJÁS- } \\
\text { PA }\end{array}$ & VISITA \\
\hline 09 & 23 & $\mathrm{M}$ & BELÉM-PA & MARABÁ-PA & CONCURSO \\
\hline 10 & 26 & $M$ & PALMAS-TO & PACAJÁ-PA & LAZER \\
\hline 11 & 35 & $\mathrm{~F}$ & XINGUARA-PA & MARABÁ-PA & TRABALHO \\
\hline 12 & 20 & $\mathrm{M}$ & MARABÁ-PA & IMPERATRIZ-MA & $\begin{array}{c}\text { TRANSPORT } \\
\text { E DE } \\
\text { CARGAS }\end{array}$ \\
\hline 13 & 35 & $\mathrm{M}$ & TOMÉ-AÇU-PA & ALTAMIRA-PA & TRABALHO \\
\hline 14 & 20 & $M$ & $\begin{array}{c}\text { SÃO PEDRO DA ÁGUA } \\
\text { BRANCA-MA }\end{array}$ & MARABÁ-PA & VISITA \\
\hline 15 & 20 & $F$ & $\begin{array}{l}\text { SÃO FRANCISCO } \\
\text { GRAÇA ARANHA-MA }\end{array}$ & ITUPIRANGA-PA & VISITA \\
\hline 16 & 49 & $\mathrm{M}$ & ALTAMIRA-PA & AÇAILANDIA-PA & TRABALHO \\
\hline 17 & 25 & $\mathrm{~F}$ & MARABÁ-PA & MARABÁ-PA & COMPRAS \\
\hline 18 & 20 & $\mathrm{~F}$ & MARABÁ-PA & MARABÁ-PA & TRABALHO \\
\hline 19 & 26 & $\mathrm{M}$ & $\begin{array}{c}\text { CANÃA DOS CARAJÁS- } \\
\text { PA }\end{array}$ & MARABÁ-PA & TRABALHO \\
\hline 20 & 29 & $\mathrm{M}$ & $\begin{array}{c}\text { NOVO REPARTIMENTO- } \\
\text { PA }\end{array}$ & MARABÁ-PA & NEGÓCIOS \\
\hline
\end{tabular}

Fonte - Elaborado pelos autores (2016). Em 27/8/2016 (sábado) às 11h. 
A abordagem dos passageiros nos dois terminais em dias e horários distintos foi intencionada a entender o motivo dos deslocamentos dos transeuntes, sejam os originários, sejam os que estão em passagem por Marabá. Para uma aproximação empírica do movimento, obteve-se amostragem de vinte e oito respondentes no terminal Miguel Pernambuco, construído mais recentemente, e vinte respondentes no terminal de Marabá, considerado mais antigo, totalizando quarenta e oito intervenções às pessoas em trânsito. Das quarenta e oito (48) pessoas que foram consultadas, vinte (20) responderam que seu destino era para a cidade de Marabá, e informaram que sua estadia na cidade ocorria pelos seguintes motivos: 8 (visitas), 6 (trabalho), 2 (negócios), 1 (compras), 1 (concurso), 1 (lazer), 1 (moradia).

A relação interurbana no movimento de atração para Marabá foi predominantemente de relação social (visitas) e econômicas (trabalho e negócios). Sendo assim, a relação socioeconômica que a cidade recebe se espraia pela cidade e fortalece as conexões multiescalares. Dessa maneira, a área central da Nova Marabá tem como característica espacial interurbana, um nó de articulação para os fluxos horizontais, intermediando a fluidez de pessoas para outras áreas da cidade e mesmo para o campo, além de outras cidades regionais e extrarregionais.

Entre o percurso da Nova Marabá e Cidade Nova:

Entrevistador: Por que aqui em Marabá tem três centros? Passageiro homem 1: É, a Nova, a Velha e a Cidade Nova. Entrevistador: O que faz a pessoa, por exemplo, sair de um centro para outro principalmente? Passageiro Homem 1: 0 que tem num centro não tem noutro, um melhor do que o outro. Entrevistador: 0 senhor, por exemplo, veio daqui e vai para a Cidade Nova fazer o que? Passageiro Homem 1: Não, eu vou pra 28. Na folha vinte e oito tem banana. Mas tem lugar que não tem! Tem uva, na Cidade Nova não tem! Não tem uva. Mas aqui na 28 tem, tem muita fruta! Passageiro Homem 2: O preço aqui é mais acessível. Entrevistador: E também parece que a Nova Marabá ela é mais completa. Entrevistador: O senhor é daqui de Marabá mesmo? Passageiro Homem 1: Fui criado aqui, mas nasci na Bahia. Entrevistador: E você é de onde? Passageiro Homem 2: Nasci e me criei aqui, Marabazão! 40 anos de Marabá. Passageiro Homem 1: Eu fui só criado aqui, em Marabá. Entrevistador: E aqui em Marabá o sistema de taxi-lotação é muito bom, né? Por quê? Passageiro Homem 1: Porque deu emprego pro pessoal, né! É rápido, o ônibus demora mais! O ônibus se tu for lá pra Cidade Nova no ônibus, ele vai lá na Velha primeiro, demora mais. O taxi aqui é mais rápido. Entrevistador: $\mathrm{E}$ o valor da passagem é o mesmo? Passageiro Homem1: Não, aqui é mais caro um pouquinho, um e vinte a mais. Passageiro Homem 2: Um e vinte e cinco. Entrevistador: Tá certo! E também o povo que anda de um centro a outro nem é só de Marabá, tem muita gente de fora. Passageiro Homem1: É, tem da colônia, da Cosampa. Entrevistador: E também das cidades vizinhas aí, né? Passageiro Homem 1: É. Entrevistador: E dia de sexta feira é mais movimentado? e acho que hoje já não está muito por causa do período do mês. Passageiro Homem 1: É. Entrevistador: Qual a diferença de folha pra rua? Passageiro Homem 03: Aqui é folha, quadra e lote. Folha 28, quadra 2, e vai mudando de lote. O Lote 2,3. Entrevistador: Você é marabaense mesmo? Passageiro Homem 03: Sou. Entrevistador: Você mora onde? Em qual núcleo? Passageiro Homem 03: $\mathrm{Na}$ Velha. Entrevistador: $\mathrm{E}$ o senhor, o que veio fazer aqui na Nova? Passageiro Homem 03: eu, trabalho. Eu vim resolver uns negócios, uns processos. Entrevistador: Secretaria da Fazenda, prefeitura fica tudo aqui, né? Passageiro Homem 03: É, eu vou mais tarde, mas depois eu venho. Entrevistador: Vai circular os três núcleos só hoje? Passageiro Homem 03: Vou, quase todos os dias. Entrevistador: Mas por quê? Passageiro Homem 03: Eu trabalho num escritório de contabilidade, e tem uns anos que mudou pra Cidade nova. Entrevistador: Mas, o mais completo de órgãos públicos é na Nova Marabá? Passageiro Homem 03: É, em termo de secretaria são pra cá, a prefeitura é aqui. Entrevistador: Certo! É impressão minha ou hoje o movimento na cidade não está tão grande, tá fraco! Eu acho que também tem a haver com o período do mês, já é final do mês. Aí o povo não vem fazer muitas coisas? Passageiro Homem 03: Tem uma onda de prefeitura aí, e ninguém sabe como é isso aí, mas hoje está estilo feriado! Entrevistador: você é marabaense? Passageiro Mulher 1: Não, sou não! Entrevistador: Você estava aqui na Nova Marabá? Passageiro Mulher 1: Sim. Entrevistador: E Você vai para onde? Passageiro Mulher 1: Cidade Nova. Entrevistador: O que você vai fazer lá? Passageiro Mulher 1: Não, é que eu trabalho aqui, e vou pra casa. Entrevistador: Você mora na Cidade Nova e trabalha na Nova Marabá. Aí vai em casa, almoça e volta? Passageiro Mulher 1: Não, só 4 horas trabalhadas. Entrevistador: Já foi hoje, então? Passageiro Mulher 1: Já! Entrevistador: Agora só Segunda-feira? Passageiro Mulher 1: Não, até amanhã. (Sábado). Entrevistador: Qual dos 
núcleos você prefere? Gosta mais de morar? Passageiro Mulher 1: Olha, desde que eu cheguei aqui, eu moro pra lá (Cidade Nova). Nunca morei pra cá (Nova Marabá). Então, não sei te falar. Entrevistador: Não é paraense? Passageiro Mulher 1: Não, sou maranhense. Eu moro aqui faz quatro anos. Mas eu sempre morei pra lá, nunca morei pra cá e sempre trabalhei pra cá. Eu não sei dizer a diferença, se é melhor lá ou pra cá. Eu sempre morei pra lá. Entrevistador: Marabá é bom para trabalho? Passageiro Mulher 1: É, desde que eu cheguei aqui eu nunca fiquei desempregada. Sempre trabalhei. Entrevistador: Sai de um lugar tem outro? Passageiro Mulher 1: É, na minha área tem! Entrevistador: Qual sua área? Passageiro Mulher 1: Técnica em radiologia. Entrevistador: Ah aqui, na Nova Marabá parece assim que tem mais atividade médica, né? Passageiro Mulher 1: É, porquê pra cá tem o Hospital regional e outras clinicas. Aqui na Nova tem a Unimed, tem várias clínicas também! Entrevistador: Você vai muito ao Shopping? Passageiro Mulher 1: Não, não vou! Entrevistador: Tem algum nome aqui nessa ponte? Passageiro Mulher 1: Nome? Não...Não sei te falar! Tem moço (Taxista)? Taxista: Rio Itacaiunas. Entrevistador: É o nome da ponte? Taxista: Não, a ponte está sobre o Rio Itacaiunas. Agora, o nome dela eu não sei não! Nunca ouvi falar. (Trabalho de campo, Agosto, 2016)

Ao circular entre os três centros por meio de taxi-lotação se utilizando da técnica de observação participante, mesmo que as durações das falas encerrassem quando as viagens chegavam ao fim, constatou-se a interdependência entre os centros, havendo certas especializações que estão ligadas tanto ao processo geohistórico de formação de cada núcleo quanto a processos atuais, tal como o Shopping Center Pátio Marabá e os serviços de saúde na Nova Marabá. Apoiado nas narrativas, condizem com a tradicionalidade e o comércio popular na Marabá Pioneira, além das atividades modernas na Cidade Nova, garantido a cristalização de conteúdo policêntrico em frações intraurbanas, o que promove interações espaciais.

Uma observação sobre a dinâmica da cidade é o arrefecimento da interação intraurbana na segunda quinzena do mês, deduzindo-se pelo pagamento de grande parte das instituições particulares e públicas realizado na primeira quinzena, fato que consegue impulsionar os deslocamentos mais intensos nesse período mensal.

Existe uma dinâmica interacional intraurbana que a população marabaense e flutuante desenvolve, correspondido primordialmente pela dinâmica das atividades de serviços e comércio, tendo o Shopping Center Pátio Marabá como um elo entre as três áreas centrais, marcado pelo ineditismo de práticas socioespacias via consumo, para certa parte da população.

O Shopping Center SC é um empreendimento com empresas organizadas em padrões estandardizados, logo, representantes imediatos de lógicas econômicas nacionais e globais. Assim, sua análise se torna mister para entender a dinâmica da centralidade. O SC é parte da reestruturação urbana e também indutora de novas relações de práticas espaciais, configura, assim, para o lugar de recepção, uma possibilidade de policentralidade, pois, no geral, a partir de sua instalação, há difícil reversão, isto é, muda profundamente e permanentemente a estrutura socioespacial da área e entorno.

\section{Quanto à instalação, o Shopping Center Pátio Marabá está}

"[...] localizado à margem da BR-222, no núcleo Nova Marabá, folha 30, quadra 15 , um dos eixos estruturantes mais valorizados do perímetro urbano da cidade. Este empreendimento corporativo foi construído a partir de associação entre o Grupo Leolar, o grupo AD Shopping, de capital nacional, o grupo Parkway, conglomerado norte americano que atua em diversos países. Tal empreendimento contou ainda como "braço" financiador o Banco Bradesco. O respectivo Shopping já em sua inauguração abriu com mais de 60 lojas, dentre as quais se destacam as lojas $C$ \& A, RENNER, MARIZA, RIACHUELO, POLISHOP, Boticário, além de salas de cinema Movie-com" (RODRIGUES, 2015, p. 163-164).

$\mathrm{Na}$ perspectiva do capital financeiro, o referido empreendimento se insere na estratégia de Joint venture, ou seja, associação entre empresas nacionais e internacionais, o que tende a ampliar por um lado o papel de Marabá na rede urbana e, de outro, a centralidade intra-urbana concernente ao núcleo da Nova Marabá, conquanto, os dois processos de certo modo se cooperam.

O Shopping Center Pátio Marabá é situado em frente à Faculdade Metropolitana, considerada a maior particular da cidade (cursos - graduação: Administração, Ciências Contábeis, Educação Física, 
Enfermagem, Engenharias Civil, Produção, Elétrica e Mecânica, Fisioterapia e Sistema de informação; - pós-graduação: ciências do esporte) (Fonte: www.faculdademetropolitana.com.br.). A faculdade em referência já se encontrava antes de 2013, isto é, preexistia ao SC (Trabalho de campo, 2016) sendo, portanto, um objeto espacial que influencia na centralidade intraurbana.

Intencionando estabelecer relações escalares em Marabá, especificamente, na área central da Nova Marabá, por meio do Shopping Center Pátio Marabá, foram analisadas as franquias fast food e seus níveis de atuação espacial.

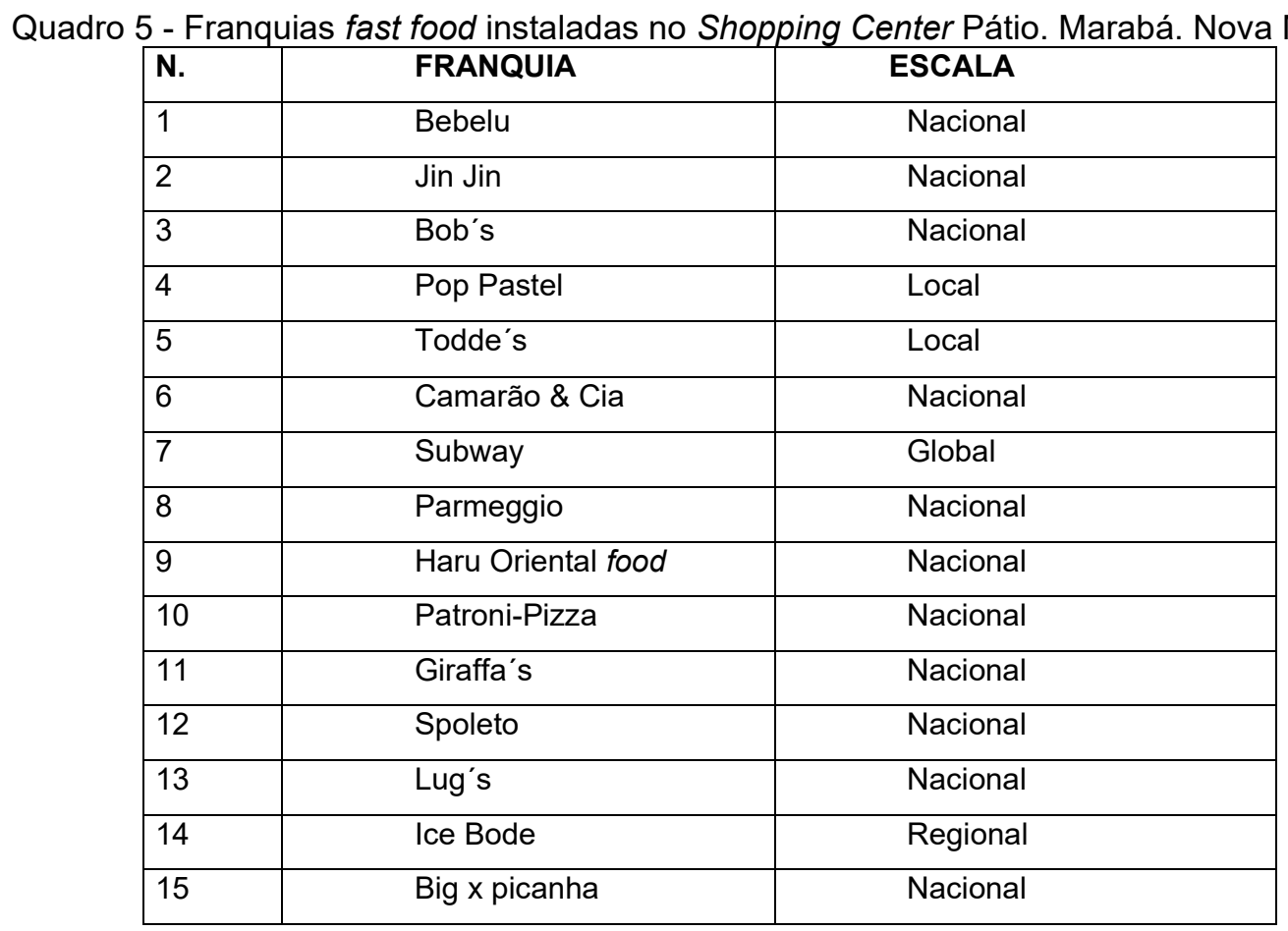

Fonte -Trabalho de campo, julho de 2018. Elaboração: Mauro Emilio, 2019.

Entre as quinze (15) franquias inseridas no SC em Marabá, duas (2) são de origem local e apenas uma (1) regional, com onze (11) nacional e apenas uma (1) global. A dimensão de atuação escalar demonstra articulações que a cidade de Marabá passa a exercer com a chegada do SC, por meio do comércio realizado pelas franquias, além da cristalização do fenômeno da policentralidade no conteúdo da área central do núcleo da Nova Marabá.

A relevância em empreender a discussão sobre o Shopping Center Pátio Marabá e o atrativo das franquias de fast food decorreu do fato de serem objeto de vanguarda quanto a equipamento moderno nas cidades em processo de reestruturação urbana, condicionando a centralidade em que, no intra-urbano, o conteúdo se modifica intensamente, seja pela ampliação dos fluxos multidirecionais, seja pela alteração de práticas espaciais.

Para Lefebvre (2013), existem vários códigos do espaço. O SC é uma prática espacial forjada de codificação, e o consumo sua descodificação. A centralidade está subordinada a práticas espaciais de consumo.

O empreendimento SC, juntamente com os dois terminais rodoviários (todos sediados na Nova Marabá) e com a orla na Marabá Pioneira, são, a sua maneira, os fragmentos da cidade de maior conexão interurbana, caracterizados como nós de articulação com o "uso" e consumo do/no espaço, contribuindo para a centralização da cidade de Marabá na rede urbana sub-regional.

\section{CONSIDERAÇÕES FINAIS}

O processo histórico do tecido urbano da cidade de Marabá teve suas formas orientadas pela ordem econômica dominante em cada momento para o atendimento de suas respectivas funcionalidades, a 
estrutura urbana da cidade compartimentada em sítios descontínuos, em que se assentou a produção espaço-tempo das áreas centrais, Marabá Pioneira, Cidade Nova e Nova Marabá.

As três áreas centrais como fragmentos que comandam a vida urbana da cidade passaram a conviver em uma relação dialética de complementação e competitividade pelo direcionamento tomado pelas outras porções espaciais da cidade. A condução do referido comando é dependente da ação e do interesse de diversos agentes.

$\mathrm{Na}$ análise, verificamos que as relações sociais (visitas) e econômicas (trabalho e negócios) foram predominantes do movimento interurbano em Marabá. Nesse sentido, há uma relação socioeconômica e conexões multiescalares, ou seja, a cidade de Marabá torna-se um polo atrativo para a população regional.

O enfoque intra-urbano se debruçou nas três áreas centrais, frações em que as técnicas que atendem as atividades de serviços e comércio são mais densas e modernas, sendo, portanto, áreas em que se dá a conjunção de múltiplas determinações. A cidade de Marabá que, em tempos, foi monocêntrica, com a expansão urbana ordenada e desordenada sob um sítio urbano cortado por dois rios, complexificou o tecido urbano ao surgir e/ou ampliar as dinâmicas espaciais de centro(s) e centralidade(s).

\section{REFERÊNCIAS}

AB'SABER, A. N. Geomorfologia do sítio urbano de São Paulo. Boletim da Faculdade de Filosofia, Ciências e Letras da USP, São Paulo, n. 219, 1957.

CORREAA, R. L. A periodização da rede urbana da Amazônia. Revista Brasileira de Geografia, Rio de Janeiro, v. 4, n. 3, p. 39-68, jul./set. 1987.

IBGE - Instituto Brasileiro de Geografia e Estatística. 2010.

LEFEBVRE, H. La producción del espacio. Madri: Capitán Swing. 2013.

MALHEIRO, B. C. P; TRINDADE JR., S. C. Entre rios, rodovias e grandes projetos: mudanças e permanências em realidades urbanas do Baixo Tocantins (Pará). In: TRINDADE JR., S. C; CARVALHO, G. Pequenas e médias cidades na Amazônia. Belém, PA: UFPA, 2009.

OLIVEIRA, J. A. As pequenas cidades da Amazônia: espaços perdidos e reencontrados. In: DAMIANI, A. L. et al. Espaço no fim do século: a nova raridade. São Paulo: Contexto. 1999.

PALHETA, S. M. et al. Geografia do espaço paraense: análises do espaço geográfico. In: PALHETA, S. M. Geografia econômica e mineração no Pará: (des) ordenamento territorial em Carajás. Belém: GAPTA/UFPA, 2014. 392 p.

PORTO-GONÇALVES, C. W. Amazônia Amazônias. São Paulo: Contexto, 2006.

PREFEITURA MUNICIPAL DE MARABÁ (PMM). Revisão do Plano Diretor Participativo de Marabá, Pará: relatório de leitura técnica. Marabá: PMM/Diagonal, 2011. 218 p.

PREFEITURA MUNICIPAL DE PARAUAPEBAS (PMP). Disponível em https://parauapebas.pa.gov.br/. Acesso em: 20 set. 2016.

RIBEIRO, R. As cidades médias e a reestruturação da rede urbana amazônica: a experiência de Marabá no Sudeste paraense. 2010. 134f. Dissertação (Mestrado em Geografia) - Universidade de São Paulo (USP). Faculdade de Filosofia, Letras e Ciências Humanas São Paulo, 2010. Disponível em: http://www.teses.usp.br/teses/disponiveis/8/8136/tde-29092010-140705/pt-br.php. Acesso em: 20 dez. 2016.

RODRIGUES, J. C. Políticas territoriais e urbanização na Amazônia oriental: estudo de Marabá. In: SILVA, C. N. et al. (org.). Sociedade, espaço e políticas territoriais na amazônia paraense. Belém: GAPTA/UFPA,2013. 
RODRIGUES, J. C. Produção das desigualdades socioespaciais em cidades médias amazônicas: análise de Santarém e Marabá, Pará. 2015. 255 f. Tese (Doutorado em Geografia) Faculdade de Ciências e Tecnologia, Universidade Estadual Paulista "Júlio de Mesquita Filho", Presidente Prudente.

SANTOS, M. A natureza do espaço: técnica e tempo: razão e emoção. 2 ed. São Paulo: Edusp, 2008a.

SANTOS, M.Técnica, Espaço, Tempo: globalização e meio técnico-científico-informacional. 5. ed. São Paulo: Edusp, 2008b.

SANTOS, M. Manual de geografia urbana. 3. ed. São Paulo: Edusp, 2012.

SPÓSITO, M. E. B. O chão em pedaços: urbanização, economia e cidades no estado de São Paulo. 2004. 508f. Tese (Livre Docência em Geografia) - Universidade Estadual Paulista, Faculdade de Ciências e Tecnologia, Presidente Prudente, 2004.

SPÓSITO, M. E. B. Segregação socioespacial e centralidade urbana. In: VASCONCELOS, P. A; CORREAA, R. L., PINTAUDI, S. M. (orgs.). A Cidade Contemporânea: Segregação espacial. São Paulo: Contexto, 2013. p. 61-94.

TRINDADE, G. O. A ver navios, barcos e canoas... vivências urbanas e relação cidade-rio na Amazônia Ribeirinha. Geografia Ensino \& Pesquisa, v. 16, n.1, p. 35-54, jan./jun. 2012. https://doi.org/10.5902/223649947321

TRINDADE JR, S. C. da. Cidades médias na Amazônia Oriental: das novas centralidades à fragmentação do território. In: ENCONTRO NACIONAL DA ANPUR, 14., 2011, Rio de Janeiro. Anais... Rio de Janeiro, 2011. https://doi.org/10.22296/2317-1529.2011v13n2p135

TRINDADE JR, S. C. da. (Sobre) vivências ribeirinhas na orla fluvial de Marabá-Pará: agentes, processos e espacialidades urbanas. In: NUNES. D. A. Novos Cadernos NAEA v. 15, n. 1, jun. 2012. https://doi.org/10.5801/ncn.v15i1.580

TRINDADE JR, S. C. da. Cidades e centralidades na Amazônia: dos diferentes ordenamentos territoriais ao processo de urbanização difusa. Revista Cidades, Presidente Prudente, v. 12, n. 21, 2015. p. 305-334.

TURRA NETO, N. Vivendo entre jovens: a observação participante como metodologia de pesquisa de campo. Revista Terr@Plural, Ponta Grossa, v. 6, n. 2, p. 241-255, jul./dez. 2012. https://doi.org/10.5212/TerraPlural.v.6i2.0004

WHITACKER, A. Centralidade intraurbana e morfologia em cidades médias: transformações e permanências. In: SEMINÁRIO INTERNACIONAL RU, 11., (Red Iberoamericana de Investigadores sobre Globalización y Território) \& TALLER RIER, 4., 2010. Anais... Mendonza: Argentina, 2010.

Recebido em: 18/10/2018

Aceito para publicação em: 17/02/2020 